\title{
Erratum to: Defining Incidence and Risk Factors of Venous Thromboembolism after Hepatectomy
}

\author{
Aslam Ejaz • Gaya Spolverato • Yuhree Kim • Donald L. Lucas • Brandyn Lau • \\ Matthew Weiss • Fabian M. Johnston • Marin Kheng • Kenzo Hirose • \\ Christopher L. Wolfgang • Elliott Haut • Timothy M. Pawlik
}

Published online: 12 February 2014

(C) 2014 The Society for Surgery of the Alimentary Tract

Erratum to: J Gastrointest Surg

DOI 10.1007/s11605-013-2432-x

This article appeared with a mistake in an author's name. "Marian Kheng" should be Marin Kheng. The corrected author list appears above.

The online version of the original article can be found at http://dx.doi.org/ 10.1007/s11605-013-2432-x.

A. Ejaz $\cdot$ G. Spolverato $\cdot$ Y. Kim $\cdot$ B. Lau $\cdot$ M. Weiss $\cdot$

F. M. Johnston $\cdot$ M. Kheng $\cdot$ K. Hirose $\cdot$ C. L. Wolfgang $\cdot$ E. Haut

T. M. Pawlik

Department of Surgery, Johns Hopkins University School of

Medicine, Baltimore, MD, USA

D. L. Lucas

Department of Surgery, Walter Reed National Military Medical

Center, Bethesda, MD, USA

T. M. Pawlik $(\bowtie)$

Department of Surgery, Johns Hopkins Hospital, 600 N. Wolfe

Street, Blalock 688, Baltimore, MD 21287, USA

e-mail: tpawlik1@jhmi.edu 